\title{
STUDIES IN INTRAVASCULAR COAGULATION. II. A COMPARI- SON OF THE EFFECT OF DICUMAROL AND HEPARIN ON CLOT FORMATION IN ISOLATED VENOUS SEGMENTS 1
}

\author{
By STANFORD WESSLER WITH THE TECHNICAL ASSISTANCE OF MARY THERESA \\ CONNELLY \\ (From the Medical Research Department of the Yamins Research Laboratory, Beth Israel \\ Hospital, and the Department of Medicine, Harvard Medical School, Boston, Mass.)
}

(Submitted for publication February 24, 1953; accepted March 25, 1953)

In a previous report (1) a method of preparing isolated blood-filled venous segments in the dog was described. Intravascular coagulation was studied by determining clot appearance, prothrombin consumption, accelerator formation and platelet disappearance within these segments. Of particular interest was the observation that a fibrin clot developed prior to the disappearance of demonstrable amounts of prothrombin or the elaboration of measurable quantities of clot accelerators. Since dicumarol-induced hypoprothrombinemia is currently employed to inhibit or retard intravascular coagulation in man, it became important to ascertain whether induced hypoprothrombinemia actually was associated with retarded fibrin deposition in vivo under the same experimental conditions. For purposes of comparison the effect of heparin was also-studied.

\section{OBSERVATIONS}

Dicumarol was administered orally to 18 dogs. After two-stage prothrombin concentrations (2) were decreased to values ranging from 29 to 2 per cent of the control level, the external jugular and femoral veins were exposed, isolated, and their contents examined as previously described (1). In brief, all demonstrable tributaries to these veins were carefully ligated and cut so that the vessels were entirely freed from surrounding structures. Continuity of each vein with the remainder of the circulation was then interrupted by the careful application of small clamps at each end of the freed segment. At selected intervals vein segments were removed from the animal and by release of one clamp the contents were emptied into clear shallow glass dishes containing 2 to 3 cc. of 2.5 per cent citrate. These dishes were carefully inspected for the presence or absence of a gross clot. Because in untreated animals clotting always occurred in

1 This investigation was supported by the Medical Research and Development Board, Office of the Surgeon General, Department of the Army, under contract No. DA-49-007-MD-220. segments isolated for one and one-half hours (1), the failure of a clot to develop within 90 minutes after isolation of a segment was accepted as evidence of clot inhibition.

Since in clinical practice the degree of hypoprothrombinemia is usually estimated by the one-stage method, such determinations ( 3 ) also were carried out in eight animals. In each such instance prothrombic activity was reduced to less than 12 per cent. Although in most dogs the degree of induced hypoprothrombinemia was far in excess of that attained therapeutically in man, in vivo clotting in the isolated venous segment was not significantly retarded (i.e. more than 90 minutes) except in one animal

TABLE I

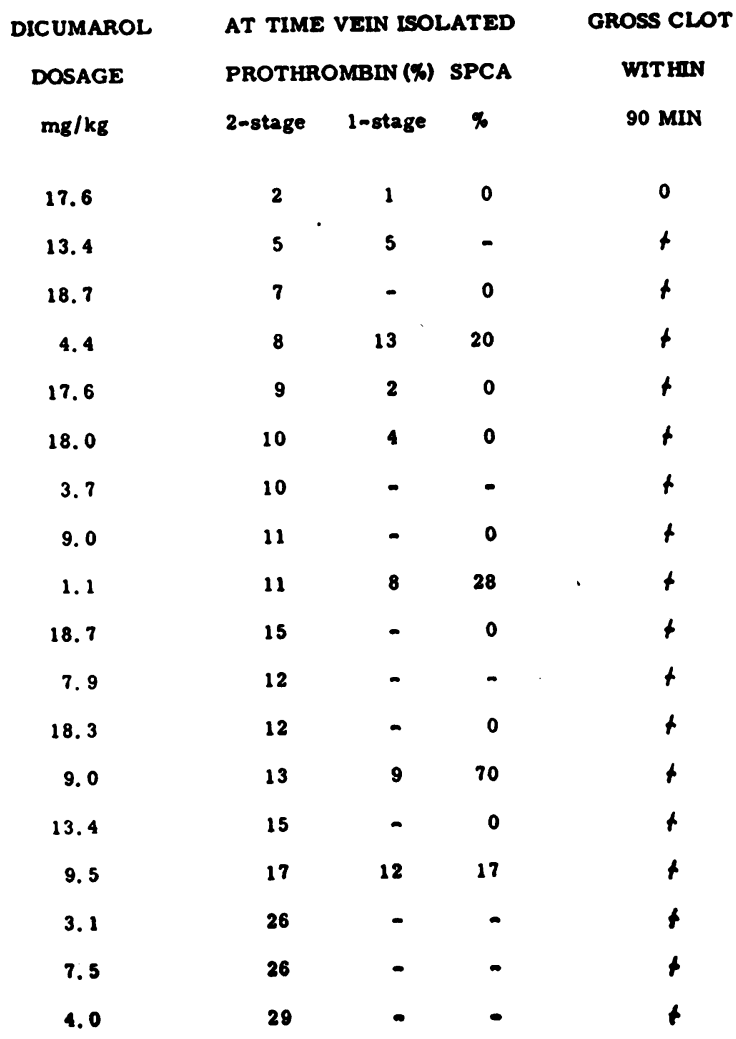


(Table I). In this dog the coagulation defect was greater than in any of the other animals: the two-stage prothrombic activity was 2 per cent and the one-stage activity less than 1 per cent of the control values; the clotting time was prolonged to three hours.

The possibility was considered that serum prothrombin conversion accelerator activity (SPCA) had not been adequately depressed by the dicumarol and was responsible for the prompt clotting in the dicumarolized segments. However, estimations of serum SPCA activity by the method of Alexander (4) in twelve of the dicumarolized dogs revealed no SPCA activity in eight (Table I).

The effect of heparin in therapeutic doses was studied in 17 dogs (Table II). In ten of eleven animals, in which the vein was isolated 30 to 60 minutes after the administration of heparin, clotting did not appear within the vein segment for 90 or more minutes. In all eleven animals, Lee-White (5) clotting times at the moment of isolation ranged from four to more than 36 times the control values. When the period of time from the administration of heparin to the isolation of the segment was increased to two hours significant retardation of in vivo clotting could still be detected in three of six dogs. In none of these six animals did the Lee-White in vitro clotting times exceed twice the control value.

In the dicumarolized dogs there was such extensive oozing into the operative wounds, that it was impossible to maintain adequate hemostasis during the time period necessary for the isolation of the vein segments. Since bleeding to a similar extent did not occur in the hepari-
TABLE $n$

\begin{tabular}{|c|c|c|c|c|}
\hline HEPARD & DITIAL & AT TIME Vav & I IEOLATED & oross CLOT \\
\hline DOsAOE & CLotruso & Ens. ArtwR & cLotraio & WrTims \\
\hline Mako & Thes (man) & EOPARIN & THME (MIN) & $00 \mathrm{mas}$ \\
\hline 2.2 & s & $1 / 2$ & 180 \& & 0 \\
\hline 2.2 & - & $1 / 2$ & $180 \mathrm{f}$ & 0 \\
\hline 1.1 & 12 & 1 & $180 \mathrm{t}$ & 0 \\
\hline 1.1 & 8 & $1 / 2$ & $180 \mathrm{f}$ & 0 \\
\hline 1.1 & 10 & 1 & 105 & 0 \\
\hline 1.1 & 11 & 1 & 102 & 0 \\
\hline 1.1 & 17 & 1 & 80 & $t$ \\
\hline 1.1 & 10 & $1 / 2$ & $60 t$ & 0 \\
\hline 1.1 & $\theta$ & 1 & 57 & 0 \\
\hline 1.1 & 6 & 1 & 24 & 0 \\
\hline 0.55 & 10 & 1 & 30 & 0 \\
\hline 1.1 & 17 & 2 & $\mathbf{3 1}$ & 1 \\
\hline 1.1 & 17 & 2 & 20 & 1 \\
\hline 1.1 & 17 & 2 & 23 & 0 \\
\hline 1.1 & 15 & 2 & 20 & 1 \\
\hline 1.1 & 11 & 2 & 18 & 0 \\
\hline 1.1 & ? & 2 & 15 & - \\
\hline
\end{tabular}

nized dogs, it was felt that hemorrhage or its sequelae may have been a factor in the observed differences between the effects of the two anticoagulants. Consequently in eight additional animals, in which large doses of di-

TABLE III

\begin{tabular}{|c|c|c|c|c|c|c|c|}
\hline \multirow{2}{*}{$\begin{array}{l}\text { DICUMAROL } \\
\text { DOSAGE }\end{array}$} & \multirow{2}{*}{$\begin{array}{c}\text { FINAL } \\
\text { PROTHROMBLN }\end{array}$} & \multirow{2}{*}{$\begin{array}{c}\text { GROSS CLOT } \\
\text { WTTHIN }\end{array}$} & \multirow{2}{*}{$\begin{array}{l}\text { HEPARIN } \\
\text { DOSAGE }\end{array}$} & \multirow{2}{*}{$\begin{array}{l}\text { INITIAL } \\
\text { CLOTTING }\end{array}$} & \multicolumn{2}{|c|}{ AT TIME VEN ISOLATED } & \multirow{2}{*}{$\begin{array}{c}\text { GROss CLOT } \\
\text { WITHLY }\end{array}$} \\
\hline & & & & & HRS. AFT ER & CLOTTING & \\
\hline MO/KG & 2-STAGE (x) & $90 \mathrm{MIN}$ & $\mathrm{MG} / \mathrm{KG}$ & TIME (MIN) & HEPARIN & TIME (MIN) & $90 \mathrm{MIN}$ \\
\hline \multirow[t]{3}{*}{13.4} & 5 & $t$ & 0.55 & 10 & 1 & 26 & 0 \\
\hline & & & & & 2 & 23 & 0 \\
\hline & & & & & 3 & 20 & $t$ \\
\hline 18.7 & $?$ & $t$ & 0.55 & 17 & 1 & 60 & 0 \\
\hline \multirow[t]{2}{*}{4.4} & 3 & $t$ & 1.1 & 18 & 1 & $180 t$ & 0 \\
\hline & & & & & 2 & 33 & 0 \\
\hline 9.0 & 11 & $t$ & 1.1 & 10 & $14 / 2$ & 19 & 0 \\
\hline \multirow[t]{2}{*}{1.1} & 11 & $t$ & 1.1 & 9 & 1 & 78 & 0 \\
\hline & & & & & 2 & 16 & 0 \\
\hline 18.0 & 12 & + & 0.55 & 16 & 1 & 25 & 0 \\
\hline \multirow[t]{3}{*}{9.0} & 13 & + & 1.1 & 18 & 1 & 77 & 0 \\
\hline & & & & & 2 & 24 & 0 \\
\hline & & & & & 3 & 20 & $t$ \\
\hline \multirow[t]{3}{*}{9.0} & 17 & $t$ & 1.1 & 11 & 1 & 162 & 0 \\
\hline & & & $s$ & & 2 & 28 & 0 \\
\hline & & & & & 3 & 15 & A \\
\hline
\end{tabular}


cumarol were given and in which the development of clot within 90 minutes was demonstrated, heparin was subsequently administered and additional segments isolated one, two and three hours after injection of the latter drug. In these animals clots did not develop until more than 90 minutes had elapsed in segments isolated one and two hours after heparinization (Table III). Coagulation was not significantly retarded in any vein segments isolated three hours after heparinization, despite the concomitant hypoprothrombinemia. There was, therefore, no evidence that dicumarol had even potentiated the clot retarding effect of heparin.

\section{DISCUSSION}

It has been previously reported from this laboratory that only small amounts of prothrombin need be present in the blood to produce a fibrin clot in the isolated vein segment of the dog (1). Data presented in this paper have shown that severe dicumarol-induced hypoprothrombinemia and SPCA deficiency do not retard markedly fibrin deposition in an isolated segment of vein unless sufficient dicumarol has been administered to prolong greatly the in vitro Lee-White clotting time of the blood. In contrast, heparin in therapeutic doses significantly retarded intravascular coagulation in similarly prepared venous segments.

It should be clearly understood that these observations do not preclude the possibility that dicumarol retards intravascular thrombosis nor do they demonstrate that heparin is an ideal anticoagulant. Failure to demonstrate clot inhibition with dicumarol may be inherent in the method employed. It can reasonably be argued that slight retardation of clotting in individual segments was overlooked by applying the rigid criteria of 90 minutes delay in gross clotting. Moreover, under the conditions of the experiment the blood in the segment was completely stagnant and isolated from the remainder of the circulation. Finally, the transient anticoagulant effect of heparin was readily apparent. The present study does show, however, that under comparable conditions the anticoagulant effect of heparin is superior to that of dicumarol. Similar findings have been reported by others $(6,7)$.

There is, of course, ample evidence that dicumarol does exert a retarding influence on blood coagulation in vitro (8-10) and on the development of experimental intravascular thrombosis in animals (11-18). In addition, statistical studies in man indicate that the drug produces a significant reduction in thromboembolism (19-21). Bingham, Meyer and Pohle (22) and Rogers, Barrett and Lam (18) found, however, that moderate degrees of dicumarol-induced hypoprothrombinemia did not significantly reduce the incidence of thrombosis in dogs. When the one-stage prothrombic activity was less than three per cent by the method of Quick (23), Rogers, Barrett, and Lam (18) observed not only a marked inhibition of thrombosis but also an important increase in hemorrhagic complications. Richards and Cortell (12) also successfully inhibited intravascular thrombosis with dicumarol dosages that were associated with extensive hemorrhage.

It is important to recognize that there may be a profound dissociation between bleeding and clotting. Our dicumarolized dogs, for example, hemorrhaged profusely during the operative procedures required to expose the vein segments, yet clotting appeared unaffected within the isolated vein. In man, clinical states such as polycythemia vera (24) and thrombotic thrombocytopenic purpura (25) may be attended by both hemorrhage and thrombosis. It has been reported that a prothrombin concentration of between 5 and 10 per cent determined by the method of Rosenfield and Tuft (3) can usually be regarded as safe (26), and that at this level coagulation is retarded (27). What is not known is how effective such levels are against thrombotic disorders.

In the prophylaxis and treatment of thromboembolism there is a constant search for more effective therapy. That thrombosis may occasionally "break through" apparently adequate dicumarol therapy has been reported by Wright (28). Until it is clearly demonstrated that the pathogenesis of thrombosis is the same in congestive failure, in post-operative and post-partum states, in malignancy and in apparently healthy individuals, one cannot assume that hypoprothrombinemia will provide equally effective therapy in all these conditions. It is certainly not easy to translate the results of experimental studies in animals to clinical practice. Nevertheless, the significance of the study herein reported lies in the observation that substances such as dicumarol, which depress that part of the coagulation sequence concerned with 
prothrombin conversion, may not provide as optimal an anticoagulant effect as heparin-like compounds which block fibrin deposition through other mechanisms (29-32).

\section{SUMMARY}

In experiments designed to study intravascular clotting in the isolated venous segment of the dog, the anticoagulant effect of heparin was found to be superior to that of dicumarol.

\section{REFERENCES}

1. Wessler, S., Studies in intravascular coagulation. I. Coagulation changes in isolated venous segments. J. Clin. Invest., 1952, 31, 1011.

2. Ware, A. G., and Seegers, W. H., Two-stage procedure for the quantitative determination of prothrombin concentration. Am. J. Clin. Path., 1949, 19, 471.

3. Rosenfield, R. E., and Tuft, H. S., Estimation of prothrombin level from prothrombin time. Am. J. Clin. Path., 1947, 17, 405.

4. DeVries, A., Alexander, B., and Goldstein, R., A factor in serum which accelerates the conversion of prothrombin to thrombin. I. Its determination and some physiologic and biochemical properties. Blood, 1949, 4, 247.

5. Lee, R. I., and White, P. D., A clinical study of the coagulation time of blood. Am. J. M. Sc., n.s., 1913, 145, 495.

6. Loewe, L., Hirsch, E., Grayzel, D. M., and Kashdan, F., Experimental study of the comparative action of heparin and dicumarol on the in vivo clot. J. Lab. \& Clin. Med., 1948, 33, 721.

7. Kiesewetter, W. B., and Shumacker, H. B., Jr., An experimental study of the comparative efficacy of heparin and dicumarol in the prevention of arterial and venous thrombosis. Surg., Gynec. \& Obst., 1948, 86, 687.

8. Butt, H. R., Allen, E. V., and Bollman, J. L., A preparation from spoiled sweet clover $\left(3,3^{\prime}\right.$-methylene-bis-[4-hydroxycoumarin]) which prolongs coagulation and prothrombin time of the blood: preliminary report of experimental and clinical studies. Proc. Staff Meet., Mayo Clin., 1941, 16, 388.

9. Moloney, W. C., Murphy, A. S., and Harrington, W. J., Prolongation of the coagulation of whole blood by dicumarol in man. Am. J. Med., 1948, 5, 40.

10. Margulies, H., and Barker, N. W., The coagulation time of blood in silicone tubes in patients receiving dicumarol. Am. J. M. Sc., n.s., 1949, 218, 52.
11. Dale, D. U., and Jaques, L. B., The prevention of experimental thrombosis by dicumarin. Canad. M. A. J., 1942, 46, 546.

12. Richards, R. K., and Cortell, R., Studies on the anticoagulant 3,3'-methylene-bis-(4-hydroxycoumarin). Proc. Soc. Exper. Biol. \& Med., 1942, 50, 237.

13. Bollman, J. L., and Preston, F. W., The effects of experimental administration of dicumarin. 3,3'methylene-bis-(4-hydroxycoumarin). J.A.M.A., 1942, 120, 1021.

14. Thill, C. J., Stafford, W. T., Spooner, M., and Meyer, O. O., Hemorrhagic agent 3,3'-methylenebis (4-hydroxycoumarin). V. Its effect in prevention of experimental thrombosis. Proc. Soc. Exper. Biol. \& Med., 1943, 54, 333.

15. Shumacker, H. B., Jr., Abramson, D. I., and Lampert, H. H., The use of anticoagulants in the surgery of aneurysms and arteriovenous fistulas, with particular reference to dicumarol. Surgery, 1947, 22, 910.

16. Varangot, J., and Vassy, S., Essais de prévention des thromboses expérimentales chez le lapin par le dicoumarol. Gynéc. et Obst., 1947, 46, 20.

17. Moss, N. H., Schafer, R. L., and Kirby, C. K., Anticoagulant effect of dicumarol at various prothrombin levels in dogs. Proc. Soc. Exper. Biol. \& Med., 1948, 69, 143.

18. Rogers, J. F., Barrett, R. J., and Lam, C. R., The effect of moderate degrees of dicumarol-induced hypoprothrombinemia on experimental intravascular thrombosis. Surg., Gynec. \& Obst., 1949, 89, 339.

19. Zilliacus, H., On the specific treatment of thrombosis and pulmonary embolism with anticoagulants, with particular reference to the post-thrombotic sequelae. The results of five years' treatment of thrombosis and pulmonary embolism at a series of Swedish hospitals during the years 1940-1945. Acta med. Scandinav., 1946, suppl. no. 171.

20. Allen, E. V., The clinical use of anti-coagulants. Report of treatment with dicumarol in 1,686 postoperative cases. J.A.M.A., 1947, 134, 323.

21. Wright, I. S., Marple, C. D., and Beck, D. F., Report of the committee for the evaluation of anticoagulants in the treatment of coronary thrombosis with myocardial infarction. (A progress report on the statistical analysis of the first 800 cases studied by this committee.) Am. Heart J., 1948, 36, 801.

22. Bingham, J. B., Meyer, O. O., and Pohle, F. J., Studies on the hemorrhagic agent $3,3^{\prime}$-methylenebis (4 hydroxycoumarin). I. Its effect on the prothrombin and coagulation time of the blood of dogs and humans. Am. J. M. Sc., n.s., 1941, 202, 563.

23. Quick, A. J., The coagulation defect in sweet clover disease and in the hemorrhagic chick disease of dietary origin. A consideration of the source of prothrombin. Am. J. Physiol., 1937, 118, 260. 
24. Alexander, B., Polycythemia. In Oxford Medicine. Vol. 2, The Oxford University Press, New York, 1947, p. 766.

25. Barondess, J. A., Thrombotic thrombocytopenic purpura. Review of the literature and report of three cases. Am. J. Med., 1952, 13, 294.

26. Alexander, B., DeVries, A., and Goldstein, R., Prothrombin: A critique of methods for its determination and their clinical significance. New England J. Med., 1949, 240, 403.

27. Alexander, B., DeVries, A., and Goldstein, R., A factor in serum which accelerates conversion of prothrombin to thrombin. II. Its evolution with special reference to the influence of conditions which affect blood coagulation. Blood, 1949, 4, 739.

28. Wright, I. S., The pathogenesis and treatment of thrombosis with a clinical and laboratory guide to anticoagulant therapy. Grune and Stratton, New York, 1952, p. 17.

29. Quick, A. J., On the action of heparin and its relation to thromboplastin. Am. J. Physiol., 1936, 115, 317.

30. Brinkhous, K. M., Smith, H. P., Warner, E. D., and Seegers, W. H., The inhibition of blood clotting: An unidentified substance which acts in conjunction with heparin to prevent the conversion of prothrombin into thrombin. Am. J. Physiol., 1939, $125,683$.

31. Wright, H. P., The adhesiveness of blood platelets in normal subjects with varying concentrations of anti-coagulants. J. Path. \& Bact., 1941, 53, 255.

32. Jorpes, J. E., Anticoagulant therapy in thrombosis. Edinburgh M. J., 1946, 53, 222. 